\title{
Beniseed Diet Moderates Blood Glucose and Body Weght in Rat Fed High Sucrose Diet
}

\author{
Adeyanju M.M. ${ }^{1}$, Atunnise A. ${ }^{1}$ Olukanni O. D. ${ }^{2}$,Adeosun C. B. ${ }^{2}$ \\ and Salau B. A. ${ }^{2 *}$ \\ 1Department of Biochemistry, faculty of Basic Medical Sciences ObafemiAwolowo College of health sciences \\ OlabisiOnabanjo University Ogun State Nigeria. \\ 2 Department of chemical sciences, College of Natural Sciences, Redeemer's University, Km. 46 Lagos/Ibadan \\ Expressway, P.M.B. 3005, Redemption City, Mowe, Ogun state, Nigeria.
}

\begin{abstract}
Effects of beniseed diet were assessed on forty(48)weanling male albino rats divided into four equal groups as follows: G1(control group given rat chow only), G2(rat chow and sucrose), G3(rat chow and beniseed) and G4(rat chow, sucrose and beniseed). Initial blood glucose and body weight were taking at first week while the final parameters were taking at eighth week. Blood glucose and oral tolerance test was carried out using glucometer while body weight was measured using the weighing scale. Present results indicated that beniseed diet moderates blood glucose in rat fed high sucrose diet but did not affect body weight.
\end{abstract}

Keywords: beniseed diet, fasting blood glucose, body weight, oral Glucose tolerance test.

\section{Introduction}

Sucrose diet has been shown to cause different disorders in humans and animal models (Salau et al.,2013; Salau et al., 2012;Sivabalan and Menon, 2008) some of those abnormalities include derangement in fasting blood glucose, oral glucose tolerance test and body weight (Salau et al., et al. 2011; Saris, 2003). However, intake of other dietary components may have a moderating effect on some of these parameters. Few of these food components are fibers,proteins and other phytochemicals which have been shown to have beneficial effect on these disorders (Lan-Pidhainyand Wolever, 2010; Anderson and Akanji, 1993).

Beniseed(sesame indicum)belongs to the pedaliaceae family and is cultivated in several countries. It uses as nutraceuticals which includes antioxidants, hepatoprotection cancer and heart disease prevention have been documented (Cooney et al., 2001). However, there is dearth of information on effect of beniseed on high sucrose diet.

In view of the above, the effect of beniseed on high sucrose diet was investigated as possible implication on body weight and blood glucose status.

\section{Materials And Methods}

\section{Experimental animals}

Forty weanling male Wister rats purchased from the animal house, physiology department, university of Ibadan, Ibadan were used for this experiment. The whole experiment was carried out in 2012 for a period of eleven weeks between August and November. The rats' weights ranged between 45-75 g. The rats were acclimatized for 2 weeks water and rat chow was given ad libtum.

\section{Feed preparation}

The pellet(rat chow) obtained from Ladokun feeds Ibadan Nigeria were grinded with industrial machine, also the beniseed which was de-hulled and dried were grinded with the same machine and they were mixed according to different requirement of each group pelletized, oven dried and kept in air polythene bag.

\section{Grouping and management of animals}

Group 1(G1, Normal control): Rats in these groups were placed on commercial diet (rat chow).

Group 2(G2,test group 1): rats in these group were place on experimental diet consisting of 30\% energy supply from sucrose and $70 \%$ supply from rat chow.

Group 3( G3, test group 3): rats in these group were placed on experimental diet consisting of $30 \%$ energy supply from sucrose, $15 \%$ energy supply from beniseed and 55\% energy supply from rat chow.

Group 4(G4, test group 3): rats in these groups were placed on experimental diet consisting of $15 \%$ energy supply from beniseed and $85 \%$ energy supply from rat chow.

The rats were maintained on each diet ad libtum for periods of 4 and 8 weeks while the weights were recorded fortnightly. 
Anthropometric measurement

(a) Weight determination

After acclimation, the body weights of rats in different groups were determined using digital scale and recorded at week one (initial weight) and week eight (final weight).

(b) Body Mass Index determination.

The length of rats in different groups were determined (in meter) using meter rule by measuring from the tip of the tail to the nose and recoded at initial and the end of the experiment, while the length was divided by the weight $(\mathrm{Kg})$ to calculate the BMI.

\section{Biochemical analysis}

(a) Determination of fasting blood glucose

After 8 weeks of feeding, the animals were fasted for 12 hours. The tip of the tail of each animal was cut and drop of blood was put on a glucometer (life scan glucometer) using life scan test strip code 10 and the glucose readings were recorded.

(b) Determination of oral glucose tolerance test

This was carried out at the end of $8^{\text {th }}$ week after the rats were fasted overnight. Glucose solution was prepared by dissolving $10 \mathrm{~g}$ glucose into $40 \mathrm{ml}$ of distilled water (to read $0.25 \mathrm{~g} / \mathrm{ml}$ ). $1 \mathrm{ml}$ of solution is given to each rat (approximately $1 \mathrm{~g}$ glucose per kilogram body weight. (American diabetics association, 2009:WHO, 1980) and the blood glucose levels were taken immediately to serve as starting points while subsequent readings were taken at 30 minutes intervals for 2 hours using the method described above.

\section{Statistical Analysis}

Body weights and fasting blood glucose are expressed as means \pm standard error of mean, analyzed by SPSS 15. Difference between groups were considered significant at $\mathrm{p}<0.05$ levels.

\section{Results}

Table 1: Body weight of rats consuming Sucrose and Beniseed diets

\begin{tabular}{llll}
\hline GROUP & INTIAL & FINAL & \% CHANGE IN WEIGHT \\
\hline G1 & $103.75 \pm 8.65^{\mathrm{b}}$ & $170.00 \pm 6.26^{\mathrm{b}}$ & $68.68 \pm 8.80$ \\
G2 & $78.75 \pm 4.41^{\mathrm{a}}$ & $138.75 \pm 7.43^{\mathrm{a}}$ & $78.42 \pm 10.18$ \\
G3 & $100.00 \pm 7.07^{\mathrm{a}, \mathrm{b}}$ & $177.50 \pm 10.31^{\mathrm{b}}$ & $78.34 \pm 7.88$ \\
G4 & $86.25 \pm 7.54^{\mathrm{a}, \mathrm{b}}$ & $158.75 \pm 6.67^{\mathrm{a}, \mathrm{b}}$ & $94.97 \pm 20.94$ \\
\hline
\end{tabular}

Values are mean \pm SEM of 8 determinations, Values in the same column with different superscripts are significantly different from each other $(\mathrm{p}<0.05)$.

Table 2: Body Mass Index of rats consuming Sucrose and Beniseed diets

\begin{tabular}{lll}
\hline GROUP & INTIAL & FINAL \\
\hline G1 & $0.68 \pm 0.04^{\mathrm{a}, \mathrm{b}}$ & $0.66 \pm 0.03$ \\
G2 & $0.72 \pm 0.02^{\mathrm{b}}$ & $0.69 \pm 0.02$ \\
G3 & $0.62 \pm 0.03^{\mathrm{a}}$ & $0.62 \pm 0.09$ \\
G4 & $0.69 \pm 0.01^{\mathrm{a}, \mathrm{b}}$ & $0.69 \pm 0.03$ \\
\hline
\end{tabular}

Values are mean \pm SEM of 8 determinations, Values in the same column with different superscripts are significantly different from each other $(\mathrm{p}<0.05)$.

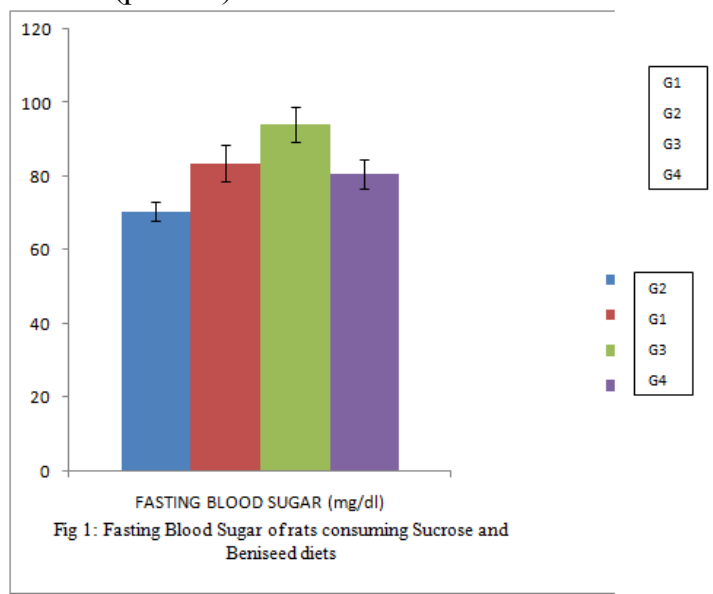




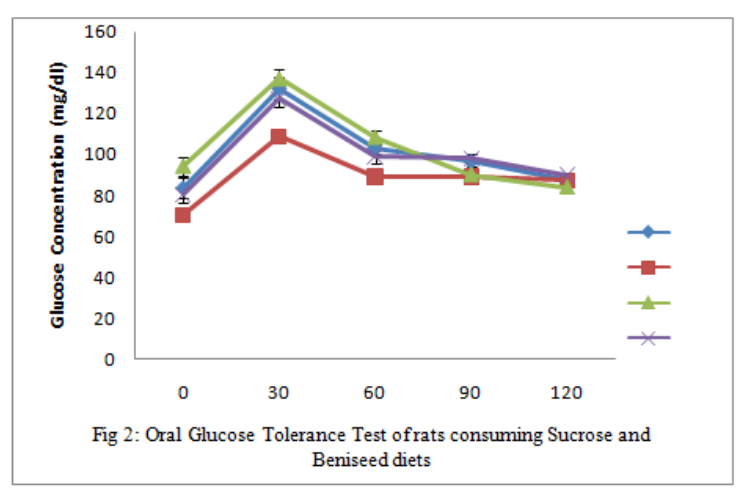

Table 1 showed the percentage change in body weight of rat fed different diets. Increase was observed when the initial weight was compared with the final weight in each group after 8 weeks of feeding. However, no significant difference $(\mathrm{p}>0.05)$ was observed in percentage weight change between the groups, also no significant difference between groups 2 and 4 but significant difference $(p<0.05)$ exists when group 2 was compared with Group 1.

Shown in table 2 is the BMI (body mass index) of the rats fed different diets, no significant difference $(p>0.05)$ was observed between initial and the final BMIin all the groups. Also no significant difference ( $>$ 0.05 ) was observed from one group to another in the final BMI, however, significant difference was observed in initial BMI of Group2 and Group3.

Figure 1 showed fasting blood glucose of rat fed different types of diet. Lowest fasting blood glucose $70.50+-2.61 \mathrm{mg} / \mathrm{dl}$ was observed in rat fed with sucrose diet (Group2) which was significantly lower $(\mathrm{p}<0.05)$ than other groups i.e.Group1 83.75+-4.88: (Group4) 80.77+-1.98 and (Group3) 94.25+-4.67. Also significant difference( $p>0.05$ ) was observed between(Group3) and (Group4).

Figure 2 showed oral glucose tolerance test, sucrose diet (Group2) has the lower level of fasting blood glucose virtually at every stage compared with other groups: followed by beniseed group (Group4), control group (Group1) while Group3 was observed to be the highest for the first one hour.

\section{Discussion}

Various investigators have shown effect of diet on body weight and blood glucose (Salau et al., 2011; Jurdak and Kanarek, 2009), while some diets may have beneficial effect on these parameters (Swinburn et al., 2004; WHO, 2000) some may have adverse effects (Salau et al., 2012). Sucrose has been shown to reduce fasting blood glucose, alters oral glucose tolerance test and increase body weight when consumed for a long period of time (Salua et al., 2011). However, this present study showed the moderating effect ofbeniseed diet on blood glucose and body weight of rat fed high sucrose diet.

Effect of sucrose diet on body weight is still controversial and inconclusive (Food and Nutrition board, 2005; WHO/FAO, 2003) while some investigators reported increase in body weight of rats consuming sucrose diet,(Craig, 2013; Salau et al 2011;Kaga, et al. 2001), contrary view was reported by other investigators who showed no change in total body weight when compared with control.(Toidas, 1996; Russell et al., 1993).This study demonstrated diets comprising sucrose and beniseed may not affect body weight. Insignificant difference $(p>0.05)$ in percentage weight change in different groups suggests changes that might be occasioned by the different diets may not be manifested probably due to short term of feeding(eight weeks of feeding.) and also the isocaloric nature of the different diets used.

Beniseed oil has been shown to reduce BMI in hypertensive subjects (Sankar et al., 2006) but in this study no significant difference ( $>0.05)$ was observed in the initial and final BMI of each group. Also there is no difference between the groups of BMI showing that the moderating effect of beniseed component such as it oil may be more effective in diseased condition.

Fasting blood glucose (FBS) is one of the parameters affected by dietary factors especially sucrose (Salau et al.,2011), Anomaly in FBG is a predisposing factor to many diseases such as diabetes, hypertension and metabolic syndrome $\mathrm{X}$. In this study, sucrose diet reduced fasting blood glucose as reported in theearlier study (Salau et al., 2011). However, in this study beniseed diet improved fasting blood glucose of rats consuming high sucrose diet which may be as a result of various components such as fibers, oil and other phytochemicals (Sankar et al ., 2010), that may reduce body weight.

Oral glucose tolerance test is used to determine body response to glucose loading and it helps in predicting diseases such as cardiovascular diseases, diabetics and metabolic syndrome. Sesame oil has been shown to improve the OGTT after 120minutes (American Diabetes Association, 2012.),also corroborated by this study, the blood glucose after 120 minutes was found to be lowest in rat groups consuming sucrose diet and 
beniseed. Also the result in figure 2 showed that rat in different groups consuming any of these diet(i.e. control and experimental) were not adversely affected in their oral glucose tolerance test as the fasting blood glucose tends to the normal after $2 \mathrm{hrs}$ with all falling between 80 and $90 \mathrm{mg} / \mathrm{dl}$.

\section{Conclusion}

The study demonstrated the ameliorative effect of beniseed diet on blood glucose and body weight of rat consuming high sucrose diet suggesting moderate consumption of beniseed may have beneficial effect on glucose metabolism.

\section{Acknowledgement}

We acknowledge the support of the head of the department of chemical sciences Redeemers University for giving laboratory space of this work and we also acknowledge Basirat Akinpelu who typed the manuscript.

\section{References}

[1]. American Diabetes Association and the European Association for the Study of Diabetes.Diabetes Care, 32, (1)

[2]. American Diabetes Association, 2009.Standards of Medical Care in Diabetes.Diabetes Care January 2009 vol. 32 no. Su pplement 1 S13-S61.

[3]. American Diabetes Association.Standards of medical care in diabetes, 2012. Diabetes Care; 35 Suppl 1:S11-63.

[4]. Anderson, J. W. \&Akanji, A. O., 1993 Treatment of diabetes with high fiber diets. In: CRC Handbook of Dietary Fiber in Human Nutrition (Spiller, G. A., ed.), pp. 443-470. CRC Press, Ann Arbor, MI.

[5]. B.A Salau, A.O. Ketiku, O.L. Adebayo, W.E. Olooto, E.O. Ajani and O. Osilesi, 2013. Modulation of Cardiovascular Risk Factors (Haematological and Haemorrheological Parameters) Caused by Sucrose Diet; American Journal of Biochemistry and Molecular Biology. Volume: 3 | Issue: 1 | Page No.: 119-126.

[6]. B.A. Salau, W.E. Olooto, O.L. Adebayo, E.O. Ajani, K.T. Odufuwa and J.O. Olowookere, 2012. Sucrose Diet Elevates Cardiovascular Risk Factors in Male Albino Rats. International Journal of Biological Chemistry, 6: 61-68.

[7]. BA Swinburn, I Caterson, JC Seidell and WPT James, 2004.Diet, nutrition and the prevention of excess weight gain and obesity. Public Health Nutrition: 7(1A), 123-146

[8]. Cooney, R.V., L.J. Custer, L. Okinaka, and A.A. Franke. 2001. Effects of dietary sesame seeds on plasma tocopherol levels. Nutr. Cancer 39:66-71.

[9]. David m. Nathan, John B. Buse, Mayer B. Davidson, EleFerrannini, Rury R. Holman, Robert Sherwin, Bernard Zinman, 2009. Medical Management of Hyperglycemia in Type 2 Diabetes; A Consensus Algorithm for the Initiation and Adjustment of Therapy: A consensus statement of the

[10]. Jurdak N and Kanarek RB, 2009. Sucrose-induced obesity impairs novel object recognition learning in young rats. Physiology \& Behavior Volume 96, Issue 1, Pages 1-5.

[11]. Kaga T, Inui A, Okita M, et al., 2001. Modest overexpression of neuropeptide Y in the brain leads to obesity after high-sucrose feeding. Diabetes.;50:1206-1210.

[12]. Lan-Pidhainy X, Wolever TM, 2010. The hypoglycemic effect of fat and protein is not attenuated by insulin resistance. Am J ClinNutr.;91(1):98-105.

[13]. Russell JC, Koeslag DG, Dolphin PJ, et al. (1993) Beneficial effects of acarbose in the atherosclerosis-prone JCR:LA-corpulent rat. Metabolism;42:218-223.

[14]. SalauBamideleAdewale, Ajani Emmanuel Oladipo, AdenugaGbenga A, Idowu O Gbolahan and OlootoEniolaWasiu, 2012.Implications of Dietary Sucrose on Feed Intake, Bodyweight and Blood Glucose Level of Rats.Res Bioscientia; Vol. 2. Issue 3: 7-12.

[15]. Sankar D, Rao MR.,2006.Effect of sesame oil on diuretics or Beta-blockers in the modulation of blood pressure, anthropometry, lipid profile, and redox status. Yale J BiolMed.

[16]. Sankar E, et al.,2010. Sesame oil synergistic effect with anti-diabetic medication in patients with type 2 diabetes mellitus.ClinNutr.

[17]. Saris H. M., 2003. Sugar, energy metabolism and body weight control Am. J.ClinNutri (4) (suppl) 850s - 857s.

[18]. Saris WH, Blair SN, van Baak MA, Eaton SB, Davies PS, Di Pietro L, Fogelholm M, Rissanen A, Schoeller D, Swinburn B, Tremblay A, Westerterp KR, Wyatt H., 2003. How much physical activity is enough to prevent unhealthy weight gain? Outcome of the IASO 1st Stock Conference and consensus statement.Obes Rev. 2003 May;4(2):101-14.

[19]. Sivabalan, S. and V.P. Menon, 2008.Effect of feeding high fat with or without sucrose on the development of diabetes in wistar rats. Asian J. Biochem., 3: 271-279.

[20]. The Work of WHO 1980-81. Biennial Report of the Director-General.Pp. 291.

[21]. Toida S, Takahashi M, Shimizu H, Sato N, Shimomura Y, Kobayashi I., 1996.Effect of high sucrose feeding on fat accumulation in the male Wistar rat.Obes Res.; 4:561-568.

[22]. WHO, 2000. Obesity: Preventing and Managing the Global Epidemic. Report of a WHO Consultation. WHO Technical Report Series No. 894.

[23]. Winston Craig, 2013. Health Benefits of Green Leafy Vegetables.Retrieved $6^{\text {th }}$ May, 2013.

[24]. YounosukeShinwmura.f, Isao Kobayashi, 1996. Effect of High Sucrose Feeding on Fat Accumulation in the Male Wistar Rat Obesity Research Vol. 4 No. 6 pg. 561. 